\title{
Informal Partnerships Between Nonprofits and Local Governments and the Role of Trust
}

\author{
Scott Pozil \\ Seattle, Washington \\ Anne Hacker \\ Walden University
}

\begin{abstract}
Informal partnerships between nonprofit organizations (NPOs) and local governments represent a winning combination for affective positive social change in communities. These partnerships thrive on the development and sustainment of trust as a guiding force between NPO executives and their local government counterparts. Qualitative case study research reveals such an assertion to be true, based on interviews and document reviews of informal partnerships in a metropolitan area in the Northwest United States. The implications for social change include establishing successful models of informal partnerships between NPOs and local governments that impact the social and economic well-being of communities.
\end{abstract}

Keywords: nonprofit partnerships, informal partnerships, local government partnerships, trust

\section{Introduction}

Positive social change has become a reality, because citizens benefit from informal partnerships between nonprofit organizations (NPOs) and government agencies by being provided with opportunities for health and social services, education, career and job counseling, and other cultural and economic prospects. These partnerships represent a new paradigm in relations between nonprofits and governments and could become the norm in the future, outpacing more formal contractual partnerships that have defined the interaction between the nonprofit and public sectors (Gazley, 2008). To a large extent, NPO involvement has changed the landscape to bring about lasting social and economic change that has directly benefitted citizens through providing opportunities for critical services that help communities and its peoples (Berman, 2010; Brown \& Caughlin, 2009; Gazley, 2008; Lecy \& Van Slyke, 2003; Portney \& Cuttler, 2010; Tsui, Bylander, Cho, Maybank, \& Freudenberg, 2012; Xu \& Morgan, 2012). This is one reason that partnerships between NPOs and governments are essential in the face of the many socioeconomic challenges that communities everywhere face daily (Bryson, Crosby, \& Stone, 2006).

The significance of partnerships between NPOs and the government has a long history in the United States. A classic example involves parks and recreation facilities in communities. Due to their bureaucratic nature, local governments have often found it difficult to effectively and efficiently employ programs to make such facilities accessible and useful for the local population. To overcome this, governmental entities provide resources, while nonprofits provide the know-how and community relationships to develop programs that attract community involvement.

These public-private partnerships have certain hallmarks of success. Xu and Morgan (2012) described the ideal partnership as consisting of shared goals and objectives, a mutual understanding 
of what each entity brings to the partnership and their responsibilities, respect, equality in the decision making process, accountability, and transparency. Mendel and Brudney (2012) added that through the framework of an informal partnership, the NPO fulfills a critical need that is necessary to achieve the goals and objectives of the project(s) that necessitate such partnerships. These hallmarks are reflective of relationships based on trust.

The social implications of both individual and community growth may be visible through the lens of successful informal partnerships between NPOs and governments as a result of their shared mission, vision, and goals related to their shared project. It is important to note that positive social change can result in unintended consequences in that not all people in a community may view the change as positive or believe that the services provided by the NPO and government entity are beneficial. Mill and Gray (1998) provided perspective through utilitarianism, in which positive social change is the result of everyone aiming toward the same goal, while achieving maximum positive results in an environment where everyone is equal. Maton (2008) wrote of empowerment by which those who are disadvantaged acquire the tools and the ability to transform their lives and aim toward achieving important life milestones. Mill and Gray (1998) implied that such individuals must overcome indifference and rely on their inner strengths to strive for these goals, representing a scenario that is challenging to realize.

Each informal partnership between a NPO and the government is different, but the dynamics that drive them may be similar. An understanding of these dynamics and possible paths to follow to achieve successful partnerships could prove to be useful to other NPOs and their local government partners that are attempting to deliver public services with the mission of achieving positive social change as measured by augmenting the social and economic status of individuals in communities.

\section{Informal Partnerships Between NPOs and Governments}

Informal partnerships between nonprofits and governments are a rather new phenomenon that presents opportunities and challenges to nonprofits as well as the government organizations that partner with them. Such partnerships are technically defined as not being governed by a contract or formal agreement, but through an informal collaboration where the NPO and government agency agree to cooperate for a specific reason, such as the delivery of a public service (Gazley, 2008). These nonprofit and government partnerships have primarily come to the fore at the local level, demonstrating municipal government's interest to more effectively reach communities through partnering with nonprofits (Gazley, 2008; Gazley, 2010; Smith, 2008). An important issue that has been explored is whether the evolution of partnerships between nonprofits and governments to a more informal relation has changed the dynamics of these partnerships.

At present, informal partnerships are commonly found where nonprofits and government entities are coordinating efforts to address community issues (Gazley, 2008; Sullivan, 2012). The parameters of how partnerships are formed may be different, but the dynamics that govern their existence appear to be similar to contractual partnerships (Gazley, 2008). Government agencies are still providing the financial resources and may believe they can impose their will (Gazley, 2008). Conversely, case studies demonstrate that it is possible for government agencies to transform themselves to become advisors while the nonprofits assume control of implementing service delivery (Sullivan, 2012). Governments continue to maintain fiscal accountability, if they contribute public resources, but they do so with an openness in which they collaborate with nonprofits to achieve mutual service delivery goals. 
Current realities may paint a picture where only a limited number of nonprofits have achieved informal partnerships with government entities that could be depicted as partnerships between equals that are based on trust (Gazley, 2008). The key point in this equation is trust. Partnerships that are based on trust could be sufficient even if the partners are not equal. They will work together to achieve mutually agreed upon goals and objectives. The partnership may reflect or come close to reflecting a partnership between equals, because trust has made it possible. The central objective is the development and sustainment of trust, which makes successful informal partnerships possible.

The nature of informal partnerships between NPOs and governments at the local level is important to understand, specifically how these partnerships evolve. Researchers have provided different examples of these partnerships in terms of their structure. Gazley $(2008,2010)$ stipulated that informal partnerships between NPOs and local governments have become common involving many areas of service provision. Mendel and Brudney (2012) described how NPOs are filling a critical gap within the framework of public-private partnerships involving a local government entity and a private sector company. Within this scenario, the government identifies the service that needs to be fulfilled, the private sector company brings the financial resources, and the NPO offers the knowhow to implement the service. Bryson et al. (2006) suggested that such partnership structures have become increasingly common and have proven to be successful models. Xu and Morgan (2012) added that an increasing number of NPOs and governments are directly engaging in public-private partnerships to develop and deliver public services in which they effectively and efficiently collaborate. Tsui et al. (2012) described a situation in which the local government entity and a university partner relied on NPOs to use their connections and understanding of what communities needed to improve food and health standards, specifically involving youth. These partnerships structures could be an indication that the dynamics that define partnerships between NPOs and governments are evolving along with the advent of an informal structure. One of the dynamics that is critical to successful informal NPO and government partnerships is trust.

\section{Trust and Trustworthiness}

Trust and trustworthiness are the cornerstones of a successful informal partnership between nonprofits and governments. Hardin (2002) defined the linkage between trust and trustworthiness as an encapsulated interest. Individuals seek to trust each other and become trustworthy, because they are mutually interested in doing so into the future (Hardin, 2002). Gresham, Pray, Wibulpolprasert, and Trayner (2011) asserted that the presence of trust is the key to overcoming uncertainty, because it enables the sharing of information and quick action from those involved to aim for successful results. The mutual interest is clear and well defined and it forms the core of the relationship and enables it to continue. Note that the interests of each party to be engaged in the partnership could be different, but there is some level of compatibility (Hardin, 2002). Each individual derives a benefit from being in the partnership and seeks to trust and become trustworthy so that the benefit continues. Hardin's (2002) and Gresham et al.'s (2011) perspectives are relevant to informal partnerships between NPOs and governments as the research presented below demonstrates.

The foundation of any partnership is the establishment of trust between those who are at the forefront of maintaining it, but the experts expressed differing opinions on this issue. Most of the literature on trust in relation to partnerships between nonprofits and governments discussed the importance of trust in these partnerships but offered little on how to develop and sustain trust, specifically from the viewpoint of those who are directly engaged in these partnerships. The literature provided empirical evidence that successful partnerships between NPOs and government agencies are positively correlated with trust and the associated factors that foster it. 
The definition of trust is complex, particularly as it applies to informal partnerships between NPOs and governments. Lamothe and Lamothe (2011) stated that "Trust is a multilayered concept that comprises a range of attributes such as dependability, credibility, faithfulness, and information sharing, as well as the expectation of cooperation between exchange partners" (p. 868). Researchers explained that nonprofits provide a conduit through which governments can connect with local communities and begin the process of building trust with the people (Alexander \& Nank, 2009; Berman \& West, 1995; Feiock \& Jang, 2009; Gazley, 2010; Smith, 2008). From the perspective of NPOs, trust is a critical element of how they operate and is an integral part of their vision as well as guiding the relationships with those organizations with which they partner or collaborate. The onus shifts to the government organization to develop a partnership based on trust if they wish to achieve their goal of connecting with the communities in which they serve.

Given that trust is based on the aspirations of both partners to build and sustain it, the behaviors associated with trust will become evident as the nonprofit and government partners jointly strive for positive results. Alexander and Nank (2009) and Vangen and Huxham (2003) stated that the behaviors associated with trust are the desire to build a relationship that is based on constant and consistent dialogue, joint decision-making, and predictability. Poppo, Zhou, and Ryu (2008) explained that the anticipation of an ongoing relationship is a conduit for building trust and not necessarily based on past interactions. Moreover, trust involves fairness and equity, the willingness to compromise and/or collaborate (Alexander \& Nank, 2009). Trust fosters honesty and constructive feedback that propels the partnership forward (Alexander \& Nank, 2009). Alexander and Nank stipulated that with respect to interorganizational partnerships, including those between NPOs and governments, building trust is a gradual process that may be quickly lost. Van Slyke (2006) believed that trust involves the acceptance and exposure of those engaged in the partnership to the possibility that one side might take advantage of the other. Relationships that are defined by trust can be elusive and both sides must be willing to be patient.

Trust is earned, which means that both the NPO and government partners should behave in a manner that is consistent with developing trust. The development of trust is a risky proposition (Alexander \& Nank, 2009; Vangen \& Huxham, 2003), but one that delivers enormous benefits including positive social change. An important element is the willingness of the "powerful" partners or the principal to engage in a partnership with the NPO that provides autonomy, reflects a shared vision, and fosters joint decision-making (Alexander \& Nank, 2009).

Trust is seemingly operationalized in every interaction and decision taken by the NPO and government partner. Lamothe and Lamothe (2011) defined trust as incorporating strong communication and cooperation, honesty, and a commitment to the goals of the partnership. They added that trust can be an integral part of partnerships especially through reducing transaction costs that will lead to successful results. Willem and Lucidarme (2014) asserted that there is an element of flexibility built into the partnership if trust can be established that enables the partners to overcome challenges and obstacles. Flexibility is the hallmark of any relationship, especially when both sides employ collaboration as a tool to achieving beneficial results, such as the delivery of a public service.

The motivations of nonprofit and government partners is part of the equation in determining whether or not developing trust is possible. Lamothe and Lamothe (2011) stipulated that “'Trust' in interorganizational relations focus on perceptions about the partner's behavior in economic exchanges rather than absolute beliefs or convictions regarding its evil or benevolent nature" ( $p$. 869). Seppänen, Blomqvist, and Sundqvist (2007) stated that trust is the counterweight to the perception that partners will act in an opportunistic manner thus enabling collaboration to manifest 
itself through open communication and honesty. Vangen and Huxham (2012) considered that collaboration is the mechanism for continued interaction and that trust is developed through this process. These authors believed that perceptions are critical to developing and sustaining trust. How these perceptions are managed or overcome, if negative, may depend on the willingness and openness of those involved in the partnerships.

A core component of managing perceptions with respect to the trust dynamic is the comfort level of the NPO and government partner, especially measured by their familiarity with each other. Researchers agreed that trust is about the history and the ongoing interactions between the partners, and it is about rational choices weighing the costs and benefits, meaning that it is critical to understand opportunistic behavior (Alexander \& Nank, 2009; Hardin, 2002; Lamothe \& Lamothe, 2011; Van Slyke, 2006). A looming question is how trust can be developed between partners who do not have a history of interaction. Hardin (2002) and Van Slyke (2006) linked trust to the possibility of a burgeoning relationship that will last for an extended period. Alexander and Nank (2009) stipulated that trust is about getting to know each other, but there has to be willingness to enable this process to unfold. Such a notion indicates that the speed with which trust is developed is clearly dependent on those involved and while their past history, if any, of interaction may be relevant, it is not a determinant.

\section{Methodology}

A qualitative case study was conducted involving interviews with five NPO executives at the executive director or vice president levels in December 2014. This methodology facilitated an indepth understanding of the informal partnerships from the perspective of the NPOs. Quantitative research methods may have yielded results from more sources, but the qualitative case study approach enabled a more comprehensive understanding of why trust is critical to these informal partnerships.

The NPOs were selected based on being engaged in a successful informal partnership with a local government entity. A preinterview questionnaire was utilized to understand the nature of their partnership and if such partnership was a based on mutually agreed-upon goals of positive social change through the effective and efficient delivery of a service to the community. The interviews were conducted with NPO executives in a northwest metropolitan area at their place of employment. Interview questions for the NPO executives focused on the development and sustainment of trust, how trust impacted the goals and objectives of the informal partnerships, how the nonprofits and local governments dealt with the challenges that impeded trust, and how they were resolved. The documents reviewed included materials publicly available on the NPOs' websites or publically distributed in written format.

\section{Findings on Trust}

All of the NPO executives interviewed believed that their informal partnerships with local government entities allowed them to build relationships with their government counterparts based on trust, though some expressed that challenges arose from time to time. Trust was the cornerstone that enabled their partnerships to result in positive change for the communities in which they serve. While the development and sustainment of trust varied among the partnerships, all participants referenced trust as critical. Such convictions are consistent with research which stated that trust is the single most important component that incorporates strong collaboration and shared pursuit to enable these partnerships to be successful (Alexander \& Nank, 2009; Lamothe \& Lamothe, 2011; Vangen \& Huxham, 2003). 
The role of trust in the NPO to government relationship was critical to the effective functioning of the partnership. NPO executives equated trust to developing and sustaining a positive track record, meaning each side followed words with concrete and specific actions. The NPO executives expressed the dynamics that shape trust involve subjectivity among both sides in building a long-term relationship, the reputation of the NPO as having a positive track record that will be a draw for government partnerships to work with them, transparency as a vital element to build trust, and identifying people with whom they can develop a strong rapport and build trust. The literature confirms this notion to be true in that trust is develop in anticipation of a long and stable relationship that will grow with each interaction (Hardin, 2002; Van Slyke, 2006).

\section{Strategies to Foster Trust}

The strategies involved in developing and sustaining trust is a central factor in understanding why trust is critical to these partnerships between NPOs and local governments. The NPO executives returned to the issue of transparency, meaning they are honest, act with integrity, and are straightforward with their government partner. They all conveyed that the word partner is meaningful in that without trust and transparency, a real partnership is not possible.

The NPO executives further expressed that fostering trust equates to effectively responding to challenges that might normally derail trust, including owning up to mistakes by willing to take the blame if something goes wrong, and coming up with solutions to repair the damage. One NPO participant explained this phenomenon from the perspective of their organization, especially with the intent of overcoming complicating factors that could dog the relationship by noting that honesty and integrity are the enablers to foster trust, particularly admitting any wrongdoing and quickly righting the ship. Lamothe and Lamothe (2011) supported this assertion when defining trust as incorporating strong communication and cooperation, honesty, and a commitment to the goals of the partnership.

\section{Trust and the Balance of Power}

A linkage between trust and the balance of power was the basis for the next question, in which participants were asked if such a linkage exists in their informal partnership(s) with the local government entity. All of the participants responded that there is a linkage between trust and the balance of power in their partnerships, but the reasons stated were different.

One participant described the linkage in terms of financial considerations, whereby the absence of funding or financial support from the municipality creates an environment where the NPO and local government entity are equal partners with shared goals and objectives and trust that they will follow through to make the project happen. The funding and resources could come from the municipality in the form of in-kind contributions or a third-party source or through the NPO's own resources. Another participant compared trust and power in a formal and informal partnership. The participant stated, "I think power and trust exist in both formal and informal, and I would say, trust is even higher in an informal and power is less of a deal in informal as well." The balance of power could then become a reality in an informal partnership.

A participant brought influence into the equation in that without influence, the linkage between trust and the balance of power could not exist. The ability and opportunity to influence levels the playing field, which in turn enables the two sides-NPO and government entity-to develop trust. Another participant explored cultural issues as setting the scene where trust and the balance of power come together. The participant said that understanding the dynamics of how the city works and those individuals who make key decisions is critical in their interactions with them. It would be 
difficult to develop trust-based relationships if the local government exercises their authority as a power ploy. One of the participants stated that without a trusting partner within the government entity, the balance of power is impossible. The participant's organization would then become much more vulnerable in the absence of trust. In the participant's view, "trust levels out the balance of power."

\section{Trust, Transparency, and Track Record}

Participants also mentioned that transparency and track record were critically important aspects to developing and maintaining trust. Palanski, Kahai, and Yammarino (2011) spoke of transparency, integrity, and trust in a team environment and as behaviors exhibited both in the group and individual context, which is applicable to informal partnerships between NPOs and governments. The notion is that the NPO and their local government partner will openly share and communicate information, and act in accordance with what they express, which will lead to a relationship based on trust (Palanski et al., 2011).

One participant expressed the importance of trust in an informal partnership with a local government as mutual respect and honesty between partners who jointly aspire to achieve positive social change. The participant linked trust and transparency together through the lens of integrity, in which words and deeds are aligned.

Transparency and track record are also related to perception, meaning that the NPO can overcome any misperceptions through transparency but also maintaining a strong track record. Transparency, integrity, and trust are linked, but each and every participant involved in the informal partnership must aspire to these values.

It is clear that there is a linkage between trust, transparency, and track record, but the relationship between trust and track record is a compelling one that is actually measured by positive social change while transparency may be more of a process that enables the partnership and resulting project to move forward. Mohr and Puck (2013) made the linkage between trust and performance (i.e., track record), and how performance leads to more trust. They stated that trust and performance are interchangeable as far as trust influences performance, just as performance influences trust (Mohr \& Puck, 2013).

The NPO participants interviewed agreed with this assertion. They linked trust and performance together and added that it occurs when perceptions on both sides reflect reality. A participant couched it as taking ownership, meaning being honest and consistently following through to gain a reputation that will attract other local government and entities to work with them moving forward. Another participant added that through improving their performance, the local government entity eventually upgraded their partnership. By the same token, their organization began to view the local government as a reliable and trustworthy partner who also follows through by matching words with deeds. Such actions result in positive social change, which is why trust and track record are strongly linked.

\section{Recommendations for Further Research}

An area for further research might involve the impact that philosophical or ideological alignment plays regarding the interests of the NPO and their local government partner. The data demonstrate that NPOs and local governments would be inhibited from partnering with one another in the absence of a philosophical or ideological alignment, but the literature offers minimal analysis on this point. Therefore, research into how the interests of NPO and local governments are aligned would be 
relevant in the context of informal partnerships. The participants interviewed for this research study mentioned that philosophical alignment is relevant, but as previously noted, it is an emerging concept and one that was not considered as a central component of this research.

Another area for further research involves exploring the relationships between money and trust and how they play into the partnerships between NPOs and local governments. The data from the interviews with the NPOs reveal that there could be an inverse linkage between money and trust. While any definitive determination of this relationship is beyond the scope of this study, some NPO executives expressed their frustration with their local government partner's sense of entitlement to drive the partnership by virtue of their financial contributions. These NPO executives believed such behavior changed in the context of an informal partnership. In this regard, specific influences to explore could be cultural considerations, meaning turning misperceptions into perceptions that reflect an understanding and appreciation of each other's organization and how it operates.

\section{Conclusion}

The advent of informal partnerships between NPOs and local government may be a recent phenomenon, but partnering between nonprofits and local governments has been ingrained in American society for a long time. The new phenomenon is that NPOs are ascending up the ladder to become equal partners who have earned the right to influence and take decisions that impact the nature of their partnerships with local governments. It is no longer just about the NPO's knowledge and connections to local communities; it now concerns its ability and know-how to create positive social change. NPOs have demonstrated that they are community players who can make things happen independent of local government resources or assistance, but they also believe that collaborating with local governments is much more impactful in bringing about positive social change.

The data collected for this research illustrated that NPOs can be equal partners, vis-à-vis their local government counterparts, because they are able to rise above the challenges that have presented such a scenario in the past. The issue of trust and equality in informal partnerships, while beyond the scope of this article, appears to be a defining element. In particular, money and resources, in which NPOs are developing capabilities, capacities, and the infrastructure to bring money and resources to the fore that were formerly the role of governments is an area worth exploration. In light of the anticipated 2018 federal budget (InsideGov, 2017), the dynamics of trust, alignment, and resources development within NPO and governmental partnerships may be more urgent an issue to understand. NPOs are relying on rationalized and well-conceived processes to make decisions that are informed with a clearly defined path on how to implement projects that eventually lead to positive social change. Local governments are increasingly viewing NPOs with the respect they deserve and relying on their advice to move projects forward, and trust is at the core of this development. While such scenarios are not universal, they are certainly trending in this direction.

\section{References}

Alexander, J., \& Nank, R. (2009). Public-nonprofit partnership: Realizing the new public service. Administration \& Society, 41, 364. doi:10.1177/0095399709332296

Berman, H. (2010). Meeting community needs. Inquiry, 47, 186-198. doi:10.5034/inquiryjrnl_47.03.186 
Berman, E. M., \& West, J. P. (1995). Public-private leadership and the role of nonprofit organizations in local government: The case of social services. Policy Studies Review, 14, 235-246. doi:10.1111/j.1541-1338.1995.tb00636.x

Brown, E., \& Caughlin, K. (2009). Donors, ideologues, and bureaucrats: government objectives and the performance of the nonprofit sector. Financial Accountability \& Management, 25, 99114. doi:10.1111/j.1468-0408.2008.00467.x

Bryson, J. M., Crosby, B. C., \& Stone, M. (2006). The design and implementation of cross-sector collaborations: Propositions from the literature. Public Administration Review, 66, 44-55. doi:10.1111/j.1540-6210.2006.00665.x

Feiock, R. C., \& Jang, H. (2009). Nonprofits as local government service contractors. Public Administration Review, 69, 668-680. doi:10.1111/j.1540-6210.2009.02016.x

Gazley, B. (2008). Beyond the contract: The scope and nature of informal government-nonprofit partnerships. Public Administration Review, 68, 141-154. doi:10.1111/j.15406210.2007.00844.x

Gazley, B. (2010). Why not partner with local government? Nonprofit managerial perceptions of collaborative disadvantage. Nonprofit and Voluntary Sector Quarterly, 39, 51-76. doi:10.1177/0899764008327196

Gresham, L. S., Pray, L. A., Wibulpolprasert, S., \& Trayner, B. (2011). Public-private partnerships in trust-based public health social networking: Connecting organizations for regional disease surveillance (CORDS). Journal of Commercial Biotechnology, 17, 241-247. doi:10.1057/jcb.2011.15

Hardin, R. (2002). Trust and trustworthiness. New York, NY: Russell Sage.

InsideGov. (2017). 2018 United States budget estimate. Retrieved from http://federalbudget.insidegov.com/1/121/2018-Estimate

Lamothe, M., \& Lamothe, S. (2011). To trust or not to trust? What matters in local governmentvendor relationships? Journal of Public Administration Theory and Research, 22, 867-892. doi:10.1093/jopart/mur063

Lecy, J. D., \& Van Slyke, D. M. (2013). Nonprofit sector growth and density: Testing theories of government support. Journal of Public Administration Research \& Theory, 23, 189-214. doi:10.1093/jopart/mus010

Maton, K. I. (2008). Empowering community settings: Agents of individual development, community betterment, and positive social change. American Journal of Community Psychology, 41, 421. doi:10.1007/s10464-007-9148-6

Mendel, S. C., \& Brudney, J. L. (2012). Putting the NP in PPP: The role of nonprofit organizations in public-private partnerships. Public Performance \& Management Review, 35, 617. doi:10.2753/PMR1530-9576350403

Mill, J. S., \& Gray, J. (1998). On liberty and other essays. New York, NY: Oxford University Press.

Mohr, A. T., \& Puck, J. (2013). Revisiting the trust-performance link in strategic alliances. Management International Review, 53, 269-289. doi:10.1007/s11575-012-0145-0

Palanski, M. E., Kahai, S. S., \& Yammarino, F. J. (2011). Team virtues and performance: An examination of transparency, behavioral integrity, and trust. Journal of Business Ethics, 99, 201-216. doi:10.1007/s10551-010-0650-7 
Poppo, L., Zhou, K., \& Ryu, S. (2008). Alternative origins to interorganizational trust: An interdependence perspective on the shadow of the past and the shadow of the future. Organization Science, 19, 39-55. doi:10.1287/orsc.1070.0281

Portney, K. E., \& Cuttler, Z. (2010). The local nonprofit sector and the pursuit of sustainability in American cities: A preliminary exploration. Local Environment, 15, 323-339. doi:10.1080/13549831003677704

Seppänen, R., Blomqvist, K., \& Sundqvist, S. (2007). Measuring inter-organizational trust: A critical review of the empirical research in 1990-2003. Industrial Marketing Management, 36, 249265. doi:10.1016/j.indmarman.2005.09.003

Smith, S. R. (2008). The challenge of strengthening nonprofits and civil society. Public Administration Review, 68, s132-s145. doi:10.1111/j.1540-6210.2008.00984.x

Sullivan, B. (2012). Inter-organizational relationships of health partnerships: Characteristics of the Fulton county SPARC program. Journal of Health \& Human Services Administration, 35, $44-70$.

Tsui, E., Bylander, K., Cho, M., Maybank, A., \& Freudenberg, N. (2012). Engaging youth in food activism in New York City: Lessons learned from a youth organization, health department, and university partnership. Journal of Urban Health: Bulletin of the New York Academy of Medicine, 89, 809-827. doi:10.1007/s11524-012-9684-8

Van Slyke, D. M. (2006). Agents or stewards: Using theory to understand the government-nonprofit social service contracting relationship. Journal of Public Administration Research and Theory, 17, 157-187. doi:10.1093/jopart/mul012

Vangen, S., \& Huxham, C. (2003). Nurturing collaborative relations: Building trust in interorganizational collaboration. Journal of Applied behavioral Science, 39, 5-31. doi:10.1177/0021886303039001001

Vangen, S., \& Huxham, C. (2012). The tangled web: Unraveling the principle of common goals in collaborations. Journal of Public Administration Research and Theory, 22, 731-760. doi:10.1093/jopart/mur065

Willem, A., \& Lucidarme, S. (2014) Pitfalls and challenges for trust and effectiveness in collaborative networks. Public Management Review, 16, 733-760. doi:10.1080/14719037.2012.744426

Xu, H., \& Morgan, K. (2012). Public-private partnerships for social and human services: A case study of nonprofit organizations in Alabama. Public Administration Quarterly, 36, 277-310.

The Journal of Social Change, sponsored by Walden University, welcomes manuscripts focusing on interdisciplinary research in social change that improves the human condition and moves people, groups, organizations, cultures, and society toward a more positive future.

Walden University Publishing: http://www.publishing.waldenu.edu 